few days will not lead to an immediate relapse and may induce a false optimism. Thus up to $40 \%$ of schizophrenic outpatients do not take their tablets as prescribed, ${ }^{1}$ and one in five inpatients do not take the tablets given them by the nursing staff. ${ }^{2}$ Nevertheless, relapses in schizophrenic patients are frequently directly related to stopping medication, particularly in patients whose symptoms have not completely cleared up. 18

It is, therefore, not surprising that the long-acting preparations of fluphenazine have aroused such interest among psychiatrists. These preparations have the same clinical efficacy as the oral preparations when taken regularly, and their sole advantage is that they can be given by injection at one- to four-weekly intervals. The two preparations available at present are fluphenazine enanthate and fluphenazine decanoate; the latter is longer acting and probably has less tendency to produce extrapyramidal symptoms. ${ }^{5}$ Other preparations, such as fluspirilene and a derivative of pipothiazine, are on trial on the Continent.

Many centres have developed special outpatient clinics for patients on regular injections, and follow up patients energetically if they fail to attend. The increased frequency of attendances for injections and the attention and enthusiasm which new treatments always inspire would be expected to improve the results of fluphenazine therapy compared with those using the older drugs. No double-blind controlled investigations of long-acting fluphenazines have been reported, doubtless because of the ethical difficulties of giving regular injections of a placebo to the controls. Nevertheless, the claims that hospital admissions have been reduced by over half, ${ }^{8-8}$ or that patients have shown remarkable improvement when transferred from orthodox medication, ${ }^{9}$ are striking, and it seems reasonable to attribute much of the improvement to these long-acting preparations.

The side effects of the long-acting preparations are similar to those of oral fluphenazine and other piperazine derivatives. The most important are the extrapyramidal features, especially the dystonic reactions, which may be very frightening. As always these effects are related to age and dose, and some patients appear particularly sensitive. Nevertheless, these effects seem to be especially common in the early days of treatment with the long-acting fluphenazines after which they gradually decrease. ${ }^{1011}$ Hence the dosage should be increased very gradually, and most psychiatrists prescribe oral antiparkinsonian agents as a routine, even though there is always the problem of getting the patient to take them regularly. Possibly depression is particularly common with the longacting fluphenazines, 12 though it is difficult to understand why the long-acting preparations should be more likely to cause this than the same drug given orally. Nevertheless, depression is a common feature of schizophrenia, and it is important to look out for it in all patients under treatment.

1 Renton, C. A., Affleck, J. W., Carstairs, G. M., and Forrest, A. D. Acta Psychiatria Scandinavica, 1963, 39, 548.

Hare, E. H., and Willcox, D. R. C., British Fournal of Psychiatry, 1967 $113,1435$.

- Birley, J. L. T., and Brown, G. W., British Yournal of Psychiatry, 1970,

- Van Praag, H. M., et al., Psychiatria, Neurologia, Neurochirurgia, 1970,
5 Neal, C. D., and Imlah, N. W., British Fournal of Social Psychiatry, 1968,

- Crumpton, N. E., in The Treatment of Mental Disorders in the Community, ed. G. R. Daniel and H. L. Freeman. London, Bailliére, Tindall and Cassell, 1968.

T Johnson, D. A. W., and Freeman, H., paper read at the Second Joint Meeting of the Scandinavian Society of Biological Psychiatry and the Interdisciplinary Society of Biological Psychiatry, September 1970.

- Imlah, M. W., and Murphy, K. P., paper read at the Second Joint Meeting of the Scandinavian Society of Biological Psychiatry and the Interdisciplinary Society of Biological Psychiatry, September 1970.

- Goldberg, H. L., DiMascio, A., and Chaudhury, B., Diseases of the Nervous System, 1970, 31, 46.

10 Bartholomew, A. A., Medical Fournal of Australia, 1967, 2, 66.

11 Kline, N. S., Simpson, G. M., and Swenson, J. E., Diseases of the Nervous

System, 1970, 31, 43.
Alarcon, R. de, and Carney, M. W. P., British Medical Yournal, 1969, 3, 564.

\section{Efficiency by the Book}

"Generally, gate porters are very much underoccupied. Records of incoming and outgoing vehicles and of unregistered mail are seldom used and the task of directing visitors is of limited value. It is doubtful if a manned gate lodge provides any real security against unauthorized entry. The need to continue the practice should be clearly demonstrated." This is just one of several thousand examples of didactic advice offered to hospital authorities in a new publication ${ }^{1}$ from the Department of Health.

Since 1954 over 3,000 "organization and methods" and "work" studies have been carried out in the hospital service. The practical findings from these studies have been collected together to form a guide for each of the 24 major hospital departments, together with selective bibliographies for each section. In general the advice seems practical if at times a little obvious - need we be told that a man cutting a rectangular lawn has to turn the mower round each time he comes to the end unless he is prepared to abandon the pattern of light and dark stripes? But overall the guide should prove of real value to administrators and their staff trying to run hospitals on tight budgets. It will give hospital secretaries unambiguous yardsticks to assess the efficiency of each department and to restrain the enthusiasm of some of their section managers. Furthermore the patient has not been forgotten-many of the recommendations for the outpatient department are aimed at keeping the waiting time as short as possible, while the section on catering services clearly recognizes that the consumer is the final arbiter of quality. Occasionally, however, the anonymous authors' enthusiasm runs away with them, as when they give a formula for calculating ${ }^{2}$ the number of clerks needed for a

$12 \cdot 8 \mathrm{D}+9 \mathrm{~N}+4 \cdot 8 \mathrm{~T}+1 \cdot 9(\mathrm{~A}+\mathrm{E})$

61672

-plus an addition of $10 \%$ for annual and sick leave.

1 Department of Health and Social Security, Management Services (N.H.S.) Guide to Good Practices in Hospital Administration 1, London, H.M.S.O 1971. Price $£ 1.50$.

$2 \mathrm{D}=$ discharges and deaths, $\mathrm{N}=$ new outpatient attendances, $\mathrm{T}=$ total outpatient attendances, $A=n e w$ and $E=$ total attendances at the accident and emergency department. 